\title{
Students' Personal Stories: Modular Distance Learning First Experiences in the New Normal
}

\author{
Marjorie P. Caslib ${ }^{1}$, Ronald S. Decano ${ }^{2}$ \\ ${ }^{I}$ Graduate Student, Doctor of Philosophy in Educational Management, Davao del Norte State College, Philippines \\ ${ }^{2}$ Dean, Institute of Advanced Studies, Davao del Norte State College, Philippines
}

\begin{abstract}
The pandemic has altered the lives and activities of people all across the world in ways that no one could have predicted. The once-in-a-lifetime circumstance presented both problems and opportunities to all segments of the community and society. The key purpose of this descriptive qualitative phenomenological study is to explore the personal stories of students in the modular distance learning first experiences in SY 2020-2021. Insights, opinions, and ideas were sought from six (6) low performing students through Key Informant Interview. Considering the lockdown problems, data were gathered through phone calls, and video calls and were recorded, transcribed, coded analyzed, and categorized responses into themes. Five emergent themes were generated, are as follow: (1) Poor reading comprehension level (2) Lack alternative learning materials (3) No strict daily learning routine (4) No constant communication from parents and teachers for support (5) Unmotivated learning system at home. Findings revealed that the most difficult experiences met by students are the lack of comprehension and insufficient learning resources. With these findings, the school administrator and teachers should provide necessary learning strategies and alternative resources to increase learners' performance.
\end{abstract}

Key words- Students' stories, Modular Distance Learning, New normal

\section{INTRODUCTION}

$\mathrm{T}$ The pandemic has changed people's lives and activities in unexpected ways, according to DepEd. The once-in-alifetime event brought challenges and opportunities to all segments of society.

The COVID-19 pandemic has indeed brought worries and fears especially in $t$ the health risk of the people worldwide. It affects the lives of hundreds and thousands of people and also leave a great blow to our educational landscape. With the efforts to cope the global pandemic, quarantine methods are strengthened to slow down the outbreak. Education leaders worldwide have been looking for ways how quality education can be carried out amidst the situation. "Education must continue"-this phrase becomes the Department's battle cry to push that learning must never cease even in this difficult time.

To go with this advocacy, different learning modalities have been introduced to the field, which at first caused anxieties and apprehensions to teachers, students, and parents. Although these modalities have long been used as alternative delivery modes in other countries, their acceptance here in the Philippines became generally challenging as they receive tons of criticisms in the social and mainstream media.
Of all the learning delivery modalities, Distance LearningPrinted Modules is the most popular since it does not require electronic gadgets, internet connection, and it requires minimal expenses on the part of the parents. However, it also poses a lot of concerns on the part of the teachers. First, the modular approach is undeniably difficult for slow learners or those with reading problems (struggling readers) and should only be applied to independent learners.

Individualized education is provided using modular distance learning, allowing students to employ self-learning modules (SLMs) in either print or digital format/electronic copy, depending on their needs. Additional resources, including textbooks, activity sheets, study guides, and other study tools.

Self-Learning Modules (SLMs) are self-contained, selfinstructional, self-paced, and interactive learning resources for public schools designed to help students understand a specific topic or lesson by allowing them to participate actively with the information than passively reading it. (2020, DO $018 \mathrm{~s}$ )

What makes it more difficult is that teachers have very limited means to assist in face to face is still strictly prohibited, especially to those students who do not have access to the internet. The willingness of the parents to guide and assist their children is indisputably high.

Hence, parents gradually opened their minds and hearts to the new set-up. Their willingness to guide and supervise their kids' studying is far greater than sacrificing the health and lives of their children. Hence,e question on their

In Panabo City High School, among all learning delivery modalities introduced through online survey, of all the learning delivery modalities, Distance Learning-Printed Modules has the greatest number of students who preferred the modality since it does not require electronic gadgets, internet connection and it requires minimal expenses on the part of the parent. It has become the first-ever experience by the school itself.

This study aimed to discover the challenges encountered by the slow learners or struggling readers students in the Modular Distance learning using the Self- paced Learning Modules for SY 2020-2021. Likewise, this study sought to ascertain specific interventions that would address the needs of low performing students who are having the difficulty in this new normal learning modality 


\section{MATERIALS AND METHODS}

\section{Research Design}

This qualitative-phenomenological study focused on students' different lived experiences through reliable experiences, trusted details, and references from informants' actual discussions. A qualitative design enabled the researcher to examine research questions through the use of open questions in description, analysis and interpretation (Creswell, 2009).

This research was carried out using detailed interviews of six (6) informants. The researchers studied, coded, analyzed, and categorized the gathered data that emerged into themes.

\section{Research Instrument}

This research utilized qualitative research. The research instrument used to collect data was through observation and document analysis. An in-depth interview provided much more detailed information than what is available through other data collection methods (Boyce \& Neale, 2006). An in-depth interview is conducted when you interview the studied people (individually or in groups) to express free ideas, feelings, and motivations about the subject under study (Oxman, 1998:99).

\section{Data gathering}

The research was conducted in Panabo City National High School, Panabo city. The Researcher invited six (6) students with low performance, all coming from the different grade levels, BEC curriculum through chat from messenger, zoom meeting and phone calls sent open-ended questions to get through information about their learning experiences and challenges. The informants were asked open-ended questions in order to get thorough information about their experiences in modular distance learning.

\section{Data Record Procedure}

The study anchors to the interview protocol refinement (IPR) framework, which is a four-phase method for establishing and systematically revising an interview protocol. (1) ensuring interview questions correspond with research questions, (2) developing an inquiry-based dialogue, (3) getting input on interview procedures, and (4) piloting the interview protocol are all part of the four-phase process. The IRP approach can help to improve the quality of data gained from research interviews by supporting efforts to improve the dependability of interview protocols used in qualitative research. (Yeong et al., 2018)

\section{RESULTS AND DISCUSSIONS}

The informants revealed the challenges met and how they coped up with the modular distance learning modality challenges answering the Self- paced Learning Modules (SLMs) in this new normal education despite being lowperforming and struggling readers. The responses provided by the participants paved the way to create essential themes, and these were supported and justified by the statements of the informants. Five (5) themes were generated from the experiences of the low-performance students are as follow: (1) Increasing reading comprehension level (2) Acquiring alternative learning materials (3) Maintaining a strict daily learning routine (4) Continuous communication between parents and teachers for support (5) Creating fun learning system at home.

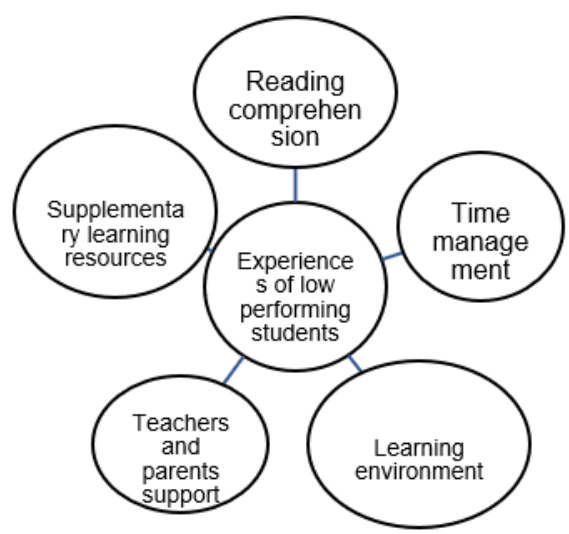

Figure 1: Generated themes of the researcher from the informants

\section{Poor reading comprehension level}

Reading is a simple approach to keep children's brains stimulated and focused during the worldwide turmoil that has created numerous impediments to education. Reading not only stimulates children's intellectual curiosity about literacy, but it also helps them develop important skills like critical thinking, creativity, and comprehension. These are critical elements in assisting students in staying connected to their learning until formal education systems have fully recovered. Reading promotes literacy, and literacy improves people's life. (Ederom 2020)

One of the informants' challenges is poor reading comprehension. The informants' main concern is inadequate comprehension; most likely, learners will not complete the module because it takes higher reading comprehension.

As such Modular Distance Learning using the self-paced learning modules due to pandemic crisis has greatly affected the students especially slow learners. They found difficulty in comprehending the text.

The information acquired indicated that learners could not comprehend what they were reading due to difficulty understanding the text itself. Due to the deployment of selfpaced learning, the learning potentials of struggling learners have been put to the test.

To overcome the difficulties faced by the struggling learners, language teachers should expand the reading and intervention program and design reading and writing to help learners improve their comprehension during this pandemic crisis.

By encouraging reading among students who have the opportunity to do so and focusing on providing educational support to those who don't, we can take small yet impactful 
steps towards combatting illiteracy during this challenging time.

\section{Lack of alternative learning materials}

The study materials have a big impact on the success and efficacy of online education systems. To meet the demands of learners, self-learning resources must make use of a variety of means and modes of communication (DepEd 2020). Any textbased or non-text-based item utilized as a major basis or as a supplement to the learning process is referred to as a Learning Resource.

The data collected disclosed that the key informants having difficulty answering the learning modules was the lack of learning resources. They sought other learning materials, printed and non-printed materials, visual, audio, digital hardware/software resources, and even human resources. It has also revealed that learners need to include learning materials that would guide and stimulate independent study/learning of the struggling learners. There's also the possibility of generating and distributing tangible take-home packages, paper worksheets, and books, as well as partnering with local television stations to broadcast educational programs, according to an EdTech article published by Micah Castel. Those are important approaches to make remote learning more accessible, especially if students can't gain internet access and do their work at a library or a local public place (Labrado et al. 2020)

It is encouraged that learners shall utilize the Learning Activity Sheets initiated by the Division office during the home learning sessions.

Resources within the locality are available not always in online resources, but with help from the community and other stakeholders.

\section{No strict daily learning routine}

Informants revealed that hard time to meet up with the deadline since time is flexible. "no one rules the time", distractions at home, such as noise, sounds from neighbors nearby, household chores, and no adequate space for the learners, siblings clamor and not enough sleep, etc. They do not have enough time to answer all the modules within a week. They wanted a proper timetable of when to wake up and sleep. The time they have to complete the task given of each subject. When to watch movies or cartoons with the family and to play online games as teenagers nowadays are influenced.

A timetable depicts the big picture and covers the most important actions that take place during the day. Routines are the steps that must be followed to complete each section of the schedule.

Learners had a predictable daily routine thanks to a constant daily timetable and step-by-step routines. Children benefit from Because they feel in control of their surroundings, they like schedules and routines in group care and at home. Feel assured, secure, and at ease.

Parents all over the world are understandably concerned about how their children's routines have been severely disturbed. To address this problem, they created homemade timetables that ensure that youngsters have something to do at all times and have a regular sleep-wake cycle. A timetable encourages youngsters to be less restless and more productive. It can also help you avoid wasting time on the internet or the computer.

Familiar activities may bring comfort for both adults and children during tough and uncertain times, according to one of the parents who wish to start and end her child's day like usual school days. When children's everyday activities are predictable and known, they, like adults, feel more confident and safer. A predictable day for children is provided by a steady daily schedule and step-by-step routines. Children benefit from schedules and routines in group care and at home because they: 1) They have a sense of control over their surroundings. 2.) Feel confident, safe, and at ease 3.) Be aware of what is going on right now and in the future. 4.) Be able to perform a task or activity. 5.) Take an active role in your education (Hermeter 2006)

The importance of adhering to the Weekly Home Learning Plan to complete the tasks in the module must be strictly monitored by parents and teachers to keep track of the day-today in-school and off-school general learning processes during the implementation of the most appropriate and feasible alternative learning modality based on their school's context.

No constant communication from teachers and fewer parents' support

Proper guidance from parents, continuous communication between the parents and teachers.

Parents play a crucial part in the learning process. They are the ones who will help and guide their children through the teachings that they would study at home. The leaners model has limited contact with teachers' placed parents or guardians. Parental encouragement has played a critical influence in successful learners' roles as educational partners and home facilitators. They are in charge of liaising with teachers, barangay leaders, and other stakeholders to obtain the various materials and resources that the students require.

Perusing exercises at home have a huge positive effect not just on understanding accomplishment, language appreciation, and expressive language abilities (Gest, Freeman, Domitrovich, and Welsh, 2004), yet in addition on understudies' advantage in perusing, mentalities toward perusing, and mindfulness in the study hall (Gest, Freeman, Domitrovich, and Welsh, 2004). (Rowe, 1991). (Clark)

Parental involvement in their children's literacy practices is more powerful than other family background variables like social class, family size, and parental education level (Flouri \& Buchanan, 2004), and that children's enjoyment of reading 
is more essential than their family's socioeconomic situation for their educational performance (Flouri \& Buchanan, 2004). The Organisation for Economic Cooperation and Development (OECD) published a report in 2002.

On the other hand, teachers play an important role in assisting students in developing and maintaining a positive attitude toward learning and literacy. They must be aware of each student's situation. Patience and love for their work are simply two factors that can help learners build a feeling of responsiveness in challenging situations. They must make an attempt to communicate with both the parents and the students.

Motivated readers read more and employ more complicated cognitive processes, resulting in improved reading skills. Even though the informants had trouble reading, they considered that their teachers and parents had been a big help in improving their reading skills.

Through their continuous hard work, the reading development of students had significantly improved.

\section{Learning system at home is bored}

It emerged in the interview that one of the challenges stated by the informants that learning at home makes them feel bored. They have no time to interact with peers. They feel tired and needed the motivation to answer the self-paced learning modules. They were tempted to play online games and tend to forget their responsibility in the modules, thus failed to answer and returned the modules on time.

You can help pupils use their knowledge and lower their affective filter by making learning pleasurable for them. Students are more likely to participate and take chances when professors use activities that make learning engaging and exciting. Students retain information better when having fun while learning since the process is engaging and memorable, just like it is for parents at home.

\section{CONCLUSION}

The Module Distance Learning responds to the call for education among students who preferred the traditional way of learning prior to the Learners Enrollment and Survey Form. Teachers hand over the printed modules to the learners' parents or guardians based on the school class schedule. After several readings of data collected, examined, and investigated, it can be concluded that.

Teachers have a great role in improving the reading problems of low-performing students. A dedicated and committed teacher has a great contribution to the students' academic life, especially in improving their reading comprehension. They are recommended to be active online most of the time to address some parents and students' sentiments and be patient enough to attend to the needs and urgent response to the queries concerning learning difficulty.
Resources within the locality are available not always in the form of online resources, but the help from the community and other stakeholders.

Students need to follow the activities in Weekly Home Learning Plan to finish the tasks in the module. Students have their learning styles that they find beneficial. Because assignments are completed at their own pace, kids develop a sense of responsibility. The teacher can assess the learners' needs and make some interventions, when necessary, using an Individual learning Monitoring Plan.

Parental Guidance is necessary in increasing students' performance. On this severe change in the educational setting produced by the covid 19 Pandemic crisis, parent support is the most important aspect contributing to the success of the school's attempts to increase the reading potential of every struggling reader. Make learning activities at home that are enjoyable.

\section{RECOMMENDATIONS}

Students should improve reading comprehension and make reading a constant practice. Teachers need to conduct a house-to-house visitation for those learners with low performance and employ reading intervention. The school must intensify the reading program giving full attention to the struggling readers. Reduction of activities from the modules. Provision of supplementary learning materials, immediate information from the teacher on what to answer in the modules, constant communication of parents and teachers to support the learners.

Parents and teachers must have collaborative efforts in the implementation of the Weekly Home Learning Plan in keeping track of the student's everyday activities. Teachers must give intervention strategies based on the Individual Monitoring Learning Plan which monitors the learner's progress to maintain a strict daily learning routine.

The language teacher must apply strategies and interventions on reading comprehension and may require students such as book reports, journal writing, reading logs, and other reading tasks in a meaningful, easy way.

The research then recommended a review of the learning activities and conduct seminars for parents to create a fun learning system and assist their children during their classes.

\section{ACKNOWLEDGEMENT}

I want to express my heartfelt appreciation to the following persons who contributed significantly to the realization of the study. Ronald S. Decano, PhD, research adviser and De of Davao del Norte State College's Graduate School, for his great motivation to accomplish this manuscript.

The members of the research committee for the insightful remarks and suggestions about the study's development. Prof. Mark Van M. Buladaco and Ma'am Gel Marie B. Tiboron, for assisting me in completing this article for publication. 
To my family, super friends, and classmates throughout my PHD journey, and Panabo City National High School colleagues who contributed to the completion of this project.

Finally, to my husband Francisco and my children Mara Ericka, and Noel Francis who showed me with love, kindness, and inspiration and provided me with moral, and spiritual support for being there throughout this endeavor.

Above all, I thank the almighty God for providing me with the power, zeal, wisdom, and peace of mind. This study would not have been possible without His Divine guidance. Marjorie

\section{REFERENCES}

[1] Clark, C. (n.d.). Why it is important to involve parents in their children's literacy. National Literacyb trust.

The Basic Education Learning Continuity Plan in the Time Of COVID-19

https://www.teacherph.com/downloaddeped-basic-educationlearning-continuity- plan-in-thetime-of-covid-19/

Najib A. Kofahi and Nowduri Srinivas (May 2004),Distance Learning: Major Issues and Challenges, May 2004 https://itdl.org/Journal/May_04/article02.htm
[2] Labrado, Gay L, Ike Paul Q Labrado, Emily C Rosal, Analiza B Layasan, Esmeralda S Salazar, Dev Ed, D Cebu Technological, et al. (2020). "RESEARCH ARTICLE NAGA- -CEBU DURING COVID-19 PANDEMIC."

[3] Pe Dangle, Ysthr Rave, and Johnine Danganan Sumaoang. (2020). "The Implementation of Modular Distance Learning in the Philippine Secondary Public Schools." Icate.

[4] Yeong, May Luu, Rosnah Ismail, Noor Hassim Ismail, and Mohd Isa Hamzah (2018). "Interview Protocol Refinement: Fine-Tuning Qualitative Research Interview Questions for Multi-Racial Populations in Malaysia." Qualitative Report 23 (11).

[5] Eleanor Edstrom (2021). "Reading During a Global Pandemic "World Literacy Foundation Organization https://worldliteracyfoundation.org/reading-during-a-globalpandemic/

[6] Dr. Jayaram, K. and Dr. Dorababu, K. K (2020). Self-learning materials in distance education system" International of current research

[7] Hemmeter, Mary Louise; Michaelene Ostrosky, and Lise Fox (2006). "Social and Emotional Foundations for Early Learning: A Conceptual Model for Intervention."School Psychology Review 35(4) (2006): 583-601. 